\title{
EDUCAÇÃO E FAKE NEWS: construindo convergências'
}

\author{
Priscila Costa Santos ${ }^{2}$ \\ Maria Elizabeth Bianconcini de Almeida ${ }^{3}$
}

\section{RESUMO}

Durante um curto espaço de tempo, as pesquisas a respeito das Redes Sociais da Internet transitaram entre um espaço de indignação e esperança, abarcando manifestações sociais em escalas globais para o materialismo da pós-verdade, chamados de Fake news. Assim, ao discorrer sobre o papel da educação no cenário das múltiplas formas e formatos de comunicação que perpassam as Redes Sociais da Internet, temos por objetivo compreender a relação entre educação e fake news a partir da constituição de rede de autores e rede de palavras-chave, identificando as possíveis convergências e perspectivas que possam ampliar a relação entre esses dois campos de estudo. Nesse sentido, para compor o cenário de reflexões, realizamos um levantamento bibliométrico das produções acadêmicas desenvolvidas no período de 2013 a 2019, disponíveis no repositório Science Direct. O exame das produções acadêmicas versou sobre o reconhecimento das fontes que contemplam o contexto da educação e das fake news, realçando as concepções e os vínculos entre ambas. A partir do software de visualização de redes, VOSviewer, apresentamos a rede de palavras-chave e a rede de autores que se sobressaem na associação entre esses campos de análise. Verificamos que as principais conexões entre educação e educação tratam sobre o desenvolvimento de habilidades para a constatação de notícias errôneas. Por sua vez, por meio da visualização da rede de palavras-chave, três palavras foram evidenciadas: educação, social media e fake news, e na rede de autores, dos 46 autores, foram criados 14 clusters.

Palavras-chave: Educação. Fake news. Mídia Social.

\section{EDUCATION AND FAKE NEWS: building convergences}

\begin{abstract}
Within a short period of time, social media research went through settings of wrath and hope, evidenced by social movements in a global scale, to the materialization of post-truth, regarded as fake news. Thus, while discussing the role of Education in

\footnotetext{
${ }^{1}$ Agradecemos à Coordenação de Aperfeiçoamento de Pessoal de Nível Superior (CAPES) pela concessão da Bolsa de Doutorado a Priscila Costa Santos, e ao Conselho Nacional de Desenvolvimento Científico e Tecnológico (CNPq) pela concessão da Bolsa de Produtividade em Pesquisa a Maria Elizabeth Bianconcini de Almeida, que possibilitaram a realização deste estudo.

${ }^{2}$ Doutoranda em Educação: Currículo pela Pontifícia Universidade Católica de São Paulo (PUC-SP). Docente da Universidade Católica de Brasília. Orcid ID: http://orcid.org/0000-00030929-698X. E-mail: pricostasantos@gmail.com.

${ }^{3}$ Livre Docente. Professora associada da Pontifícia Universidade Católica de São Paulo (PUCSP). Orcid ID: http://orcid.org/0000-0001-5793-2878. E-mail: bethalmeida@pucsp.br.
} 
multiple scenarios, considering ways and means of communication that run through Online Social Networks, - especially when it comes to the comprehension of fake news as a phenomenon - this research has the main goal to understand the relations between education and fake news, by using keywords network and the researchers network, as a way to identify possible convergences and perspectives that may increase the relations between these fields of study. In this sense, in order to build an environment of reflection, we have conducted a bibliometric study of the academic production developed from 2013 to 2019, available at the database Science Direct. The analysis of the academic production went over the identification of the sources that pond the context of education and fake news, evidencing the concepts and possible relations between these two fields of study. Besides, using the network visualization software VOSviewer, we have introduced the keywords network and the researchers network that stand out in the association of these fields of analysis. It was verified that the main relations between education and fake news concern developing skills in identifying deceptive news. The network visualization of the keywords highlighted three words: education, social media and fake news. Nevertheless, in the researchers network, fourteen clusters were created out of fortysix authors

Palavras-chave: Education. Fake news. Social Media.

\section{RESUMEN}

Durante un corto período de tiempo, la investigación en las redes sociales de Internet se movió entre un espacio de indignación y esperanza, que abarca manifestaciones sociales a escala mundial para el materialismo post-verdad, llamadas noticias falsas. Por lo tanto, al analizar el papel de la educación en el escenario de las múltiples formas y formatos de comunicación que impregnan las redes sociales de Internet, nuestro objetivo es comprender la relación entre la educación y las noticias falsas de la constitución de una red de autores y una red de clave, identificando posibles convergencias y perspectivas que pueden expandir la relación entre estos dos campos de estudio. En este sentido, para componer el escenario de reflexiones, realizamos una encuesta bibliométrica de las producciones académicas desarrolladas en el período 2013-2019, disponible en el repositorio Science Direct. El examen de las producciones académicas se ocupó del reconocimiento de fuentes que contemplan el contexto de la educación y las noticias falsas, destacando las concepciones y los vínculos entre ambas. Usando el software de visualización de red, VOSviewer, presentamos la red de palabras clave y la red de autores que se destacan en la asociación entre estos campos de análisis. Descubrimos que las principales conexiones entre educación y educación tienen que ver con el desarrollo de habilidades para encontrar noticias erróneas. A su vez, a través de la visualización de la red de palabras clave, se destacaron tres palabras: educación, redes sociales y noticias falsas, y en la red de autores, de los 46 autores, se crearon 14 grupos.

Palabras clave: Educación. Noticias falsas. Redes sociales.

\section{INTRODUÇÃO}

Com o crescimento exponencial das Tecnologias Digitais da Informação e Comunicação (TDIC) e a gradativa inclusão social dos meios digitais, aumentou-se a exposição de dicotomias que outrora eram menos 
perceptíveis e agora se tornaram palco de homéricos debates. Por um lado, são propagados enunciados que reforçam o acesso às informações, a valorização da Internet das Coisas, a Big Data como suporte para decisões e a necessidade de uma comunicação ágil como propulsora do desenvolvimento social, econômico, político e educacional. Em contrapartida, o crescente número de políticas governamentais direcionadas ao enfrentamento das notícias falsas, e do controle à privacidade e do sigilo do acesso dos dados de usuários colocam em xeque todos os impulsionadores do desenvolvimento social, econômico, político e educacional apresentados anteriormente.

Compondo essa conjuntura, as Redes Sociais da Internet, outro ponto de fissura na expansão das TDIC, como meio físico, social e comunicacional, transitam de um espaço de indignação e esperança (CASTELLS, 2013) ao materialismo da pós-verdade (FULLER, 2018). Castells (2013, p. 13) analisa as Redes Sociais da Internet a partir da capacidade de torná-las espaços de associações "entre as redes sociais da internet e as redes pessoais", forjando ou fomentando espaços e contextos de mudanças. Em contramão, esses recursos consagram a materialidade da pós-verdade, compreendendo-a como "relativo a, ou denotando circunstâncias nas quais fatos objetivos têm menos influência na formação da opinião pública do que apelos à emoção e às crenças pessoais" (ENGLISH OXFORD LIVING DICTIONARIES, 2016, s/p), e expostas em Redes Sociais da Internet.

Ao serem incluídas no debate sobre a educação, as Redes Sociais da Internet são vistas como recursos pedagógicos, aliados aos processos de ensino e de aprendizagem, contribuindo para a integração entre contextos formais e contextos informais de ensino (SANTOS; ALMEIDA, 2017), são consideradas a partir da necessidade do desenvolvimento de novos letramentos (ROJO, 2010; ROJO; MOURA, 2012) e para a educação midiática (BUCKINGHAM, 2010) a fim de identificar e entender as implicações das fake news no cenário educacional. No bojo dessa conjuntura tecnológica e social, na qual o século XXI se apresenta, o presente artigo insere-se no contexto do envolvimento das no cenário educacional, visando tecer 
caminhos para a participação da educação na compreensão e no enfrentamento das informações errôneas formando para a cidadania digital (COSTA, 2019).

Partindo da compreensão de que essas temáticas são rodeadas por campos transdisciplinares de estudo, como Comunicação Social, Linguística, Ciências Políticas e até mesmo o próprio campo educacional, julgamos necessário expor que as reflexões e as análises apresentadas neste estudo, apesar de ressaltar o contexto educacional, também permeiam outras áreas. O presente texto tem por objetivo compreender a relação entre educação e fake news a partir da constituição de rede de autores e rede de palavras-chave, identificando as possíveis convergências e perspectivas que possam ampliar a relação entre esses dois campos de estudo.

Julgamos que uma pesquisa de cunho exploratório e bibliográfico seria mais adequada para o inicial entendimento das convergências entre essas temáticas, como também para a identificação dos pesquisadores, das instituições, dos temas, teorias e metodologias que perpassam a educação e as fake news. No cenário repleto por ilimitadas contribuições acadêmicas, identificar a rede de Autores e a Rede de palavras-chaves é uma contribuição relevante para a visualização das convergências entre esses elementos.

Como questões norteadoras para este estudo propomos: Quais temas emergentes alicerçam as convergências e as perspectivas das relações entre educação e fake news? Que atenção a associação entre educação e fake news tem recebido em produções científicas, em especial no cenário educacional? Que contribuições são apontadas pela literatura no tratamento das fake news nos espaços pedagógicos?

Desse modo, organizamos o presente manuscrito em quatro seções complementares: a primeira, denominada "Flintstones e The Jetsons: uma breve reflexão sobre a cultura digital", apresenta as conjunturas sociais, culturais e educacionais que envolvem a cultura digital e as TDIC, construindo um cenário para analisarmos as convergências entre a educação e as fake news. A segunda seção, chamada "Alfabetização 
midiática e informacional e o currículo: caminhos para as fake news", expõe as acepções que perpassam os contextos de aprendizagem e os conceitos que circunscrevem o entendimento das notícias falsas, visando expor possibilidades por intermédio da alfabetização midiática e informacional e o currículo para o enfretamento das fake news.

É importante ressaltar que mesmo cientes das distinções conceituais que envolvem os termos fake news, misinformation e disinformation, ao optarmos pelo uso da expressão fake news, divulgada em meios acadêmicos e não acadêmicos, estaremos aproximando os leitores menos familiarizados a esses debates teóricos.

Enquanto o termo disinformation explora as informações falsas criadas deliberadamente para prejudicar uma pessoa, grupo social, organização ou país. As fake news têm sido comumente utilizadas como termo depreciativo para rotular fontes de notícias que não apoiam determinado posicionado perdendo a conexão com a veracidade das informações apresentadas (FLORE, BALAHUR, PODAVINI, VERILE; 2019)

A terceira seção contempla o "Design metodológico" da pesquisa. Vale destacar que o mote inicial da pesquisa está amparado em técnicas da bibliometria e análise de redes para a identificação de produções acadêmicas que versem sobre educação e fake news com vias a identificar as convergências e perspectivas que norteiam essas temáticas. Finalmente, a quarta seção apresenta os resultados da pesquisa exibindo e interpretando as redes de autores e as redes de palavras-chave.

\section{The Flintstones e The Jetsons: uma breve reflexão sobre a cultura digital}

Em meados dos anos 1960, inúmeras animações já instigavam e conduziam a imaginação dos telespectadores sobre os possíveis futuros e também sobre os possíveis passados que permearão ou permeariam a sociedade, e muitos deles ilustravam a participação e a complexidade das tecnologias, sendo elas digitais ou não, nos processos de configurações sociais. Em um paralelo, entre as animações The Flintstones e The Jetsons, ambas produzidas pelo mesmo estúdio - Hanna Barbera -, temos dois 
desenhos animados que retratam formas distintas, mas complementares, de sociedade.

Os Flintstones, ${ }^{4}$ vivendo na pré-história, trazem de forma cômica a integração entre os dinossauros, os seres humanos e as tecnologias. Ainda na abertura, Fred, um dos personagens principais, em seu trabalho utiliza um dinossauro como escavadeira; o fim do expediente é marcado pelo relógio ovacionado por um pássaro; as marcações nas pedras são registros da chegada ao cinema, que utiliza como assentos infantis dinossauros; e os carros, já com as rodas em formato redondo, são movidos pelos pés dos personagens. Essa animação é marcada pelas tecnologias não digitais, e, conforme Kenski (1998, p. 59), "quando os nossos ancestrais pré-históricos se utilizaram de galhos, pedras e ossos como ferramentas, dando-lhes múltiplas finalidades que garantissem a sobrevivência e uma melhor qualidade de vida, estavam produzindo e criando tecnologias".

Em contrapartida, em um cenário futurístico, The Jetsons ${ }^{5}$ trazem à tona a eminência da Internet das Coisas, com as casas inteligentes, carros voadores, e a ascensão de forma mais enfática dos não humanos (LATOUR, 2012) representada pela Rosie, a robô que cuida da limpeza. Nesse contexto tecnológico, a predominância das TDIC na animação é um vislumbre das potencialidades que esses recursos são capazes de produzir nos espaços de comunicação; nas formas de organização social, econômica e educacional; no rompimento com a continuidade e sequencialidade dos letramentos; na potencialidade de propagar informações em larga escala, entre outros aspectos.

Em ambos, para além da transição entre as TDIC, a compreensão de cultura, aspecto que será o mote desta seção, também é um dos elementos de destaque. Para Buzato (2010), a "cultura", em uma primeira dimensão, concentra-se como um artefato em constante mutação e renovação, capaz de direcionar os comportamentos e os sentidos sociais e individuais.

\footnotetext{
4 Vinheta de abertura dos Flintstones: https://www.youtube.com/watch? $v=$ lo5ARXRpEds. Acessado em: 4 de Janeiro de 2020.

5 Vinheta de abertura dos The Jetsons: https://www.youtube.com/watch? $v=a y w y n i q r T 3 w$. Acessado em: 4 de Janeiro de
} 
Em uma segunda dimensão, esse autor discorre sobre as relações culturais pautando que a delimitação ou descrição de uma cultura deve ser exposta a partir do encontro entre as demais culturas, ou seja, "é justamente no encontro com "as outras" que ela se constitui com "a uma" e, ao mesmo tempo, se renova e transcende seus próprios limites (BUZATO, 2010, p. 4).

Nessa perspectiva, em um primeiro momento de estudo, caberia compreender quais comportamentos e sentidos sociais e individuais permeiam determinada cultura. Em um segundo momento, a dedicação concentrar-se-ia na seleção de quais culturas seriam necessárias para o encontro entre "as outras". Diante dessa conjuntura, como as transformações culturais permeadas pelo exponencial avanço das TDIC servem de insumo para compreender a relação entre educação e fake news a partir da constituição de rede de autores e rede de palavras-chave, identificando as possíveis convergências e perspectivas que possam ampliar a relação entre esses campos de estudo?

Partindo desse questionamento, consideramos relevante para a nossa exposição discorrer sobre a realidade que perpassa as transformações culturais permeadas pelo exponencial avanço das TDIC para $O$ entendimento e contextualização das fake news. Considerando essa conjuntura, vamos compor nossa apresentação a partir de dois eixos: cultura digital: conceito e perspectivas; e cultura digital e a educação.

Ao dissertar sobre a cultura digital: conceito e perspectivas transcorrem-se a polissemia e os entendimentos vagos, genéricos em abundância que cercam sua compreensão conceitual. Nas reflexões de renomados pesquisadores (BUZATO, 2010; GERE, 2008; IANNONE; ALMEIDA; VALENTE; 2015, ALMEIDA, 2019), a conceituação de cultura digital exige dois olhares: o primeiro, ilustrado anteriormente, decorre da concepção de "cultura", e o segundo da concepção de "digital".

Reforçando as ponderações apresentadas anteriormente sobre "cultura", Buzato (2010) expõe que a cultura digital se organiza como qualquer outra cultura, sendo uma unidade em contínua modificação, heterogênea, repleta de ideias, práticas, atitudes e valores. Assim, a cultura 
digital estaria no mesmo patamar de outras culturas, como a cultura escolar, cultura empresarial, cultura da paz, cultura do funk, cultura hip-hop, entre outras.

Nessa circunstância, a expressão "digital" é a matriz que delineia ou difere a cultura digital das demais culturas. O digital, também imerso em conceitos plurais, como apresenta Gere (2008), pode ser entendido a partir do viés técnico, em que faz alusão aos sistemas tecnológicos e à capacidade de processamento de uma enormidade de dados pelos computadores. Na ótica técnica, o digital é sinônimo de tecnologia.

Em uma segunda ótica, Gere (2008), além de valorizar a complexidade dessa expressão, apresenta um entendimento mais amplo do que é digital permeado por ações individuais e coletivas que são transformadas pela virtualidade, por artefatos tecnológicos, por sistemas de sentido e significação que moldam ou envolvem a vida cotidiana.

Falar em digital é chamar, metonimicamente, toda a panóplia de simulacros virtuais, comunicação instantânea, mídia onipresente e conectividade global que constituem grande parte de nossa experiência contemporânea. [...] Também evoca todo o mundo do capitalismo conectado dominado por empresas de alta tecnologia como Microsoft e Sony e as chamadas "dot.com", empresas baseadas na Internet, que, por um tempo, pareciam apresentar 0 modelo ideal para os negócios do século XXI, bem como, de maneira mais geral, o complexo inexpugnável de negócios corporativos que, possibilitado pela alta tecnologia, opera em nível global e, às vezes, parece exercer mais poder do que os estadosnação. [...] Assim, o termo aparentemente simples digital define um conjunto complexo de fenômenos (GERE, 2008, p. 15-16).

Nesse âmbito, o desenvolvimento tecnológico teria mais relação com o desenvolvimento das culturas do que ao contrário (GERE, 2008). Pretto e Assis (2008, p. 78) acrescentam ainda que a apropriação da cultura digital é urgente, principalmente no que concerne à inclusão e à reorganização das relações sociais mediadas pelas TDIC, incluindo "reorganizações da língua escrita e falada, ideias, crenças, costumes, códigos, instituições, ferramentas, métodos de humana". Tendo em vista que as relações sociais com as TDIC são estruturantes do pensamento, dos modos de representá-lo e dos significados atribuídos, elas adentram as práticas educacionais até mesmo 
nas situações em que os dispositivos tecnológicos não estejam presentes fisicamente e provocam mudanças no desenvolvimento do currículo (IANNONE, ALMEIDA, VALENTE; 2015).

Quando assistimos aos The Flintstones ou The Jetsons, as tecnologias retratadas naquelas realidades são, em sua maioria, condizentes com a cultura do período. Em The Flintstones, as tecnologias são animadas por dinossauros atrelando à cultura pré-histórica elementos da contemporaneidade, como o carro e o relógio, adaptados para reforçar os aspectos lúdicos do desenho, respeitando, ainda assim, o período vigente e revelando um significado da tecnologia para melhorar aquilo que já se fazia sem ela. Por sua vez, as naves espaciais e os robôs sugerem mudanças nas relações entre humanos e não humanos com a participação ativa das TDIC e a preponderância da cultura digital.

No bojo dessa conjuntura tecnológica e social, são crescentes as iniciativas que se empenham em promover e discorrer sobre a cultura digital e a educação. No cenário brasileiro, as últimas reformas educacionais atribuíram especial ênfase às TDIC e às mídias. Na Base Nacional Comum Curricular (BNCC) (BRASIL, 2017), documento que normatiza as aprendizagens essenciais que os discentes devem desenvolver ao longo da educação básica, é alvitrada a necessidade de (re)pensar o uso das TDIC amparadas pelo entendimento das mudanças culturais:

Os jovens têm se engajado cada vez mais como protagonistas da
cultura digital, envolvendo-se diretamente em novas formas de
interação multimidiática e multimodal e de atuação social em rede,
que se realizam de modo cada vez mais ágil. Por sua vez, essa
cultura também apresenta forte apelo emocional e induz ao
imediatismo de respostas e a efemeridade das informações,
privilegiando análises superficiais e o uso de imagens e formas de
expressão mais sintéticas, diferentes dos modos de dizer e
argumentar característicos da vida escolar.

Nessa esfera, duas competências gerais da BNCC da educação básica são importantes para nossa discussão sobre educação e fake news. A quinta competência geral explicita os aspectos a serem observados para $\circ$ uso crítico, significativo, reflexivo e ético das TDIC, a saber: 
Compreender, utilizar e criar tecnologias digitais de informação e comunicação de forma crítica, significativa, reflexiva e ética nas diversas práticas sociais (incluindo as escolares) para se comunicar, acessar e disseminar informações, produzir conhecimentos, resolver problemas e exercer protagonismo e autoria na vida pessoal e coletiva.

Por seu turno, a sétima competência possui íntima relação com a expansão da educação científica, aspecto que também é ilustrado na BNCC. A educação científica é entendida a partir da tríade ciênciatecnologia-sociedade, em que a ciência e a tecnologia, ao serem integradas, podem, por outro lado, ser constitutivas para "a melhoria da qualidade de vida humana, mas, por outro, ampliam as desigualdades sociais e a degradação do ambiente" (BNCC, 2018, p. 327). Partindo da apreensão de que para se constituir a tríade ciência-tecnologia-sociedade são necessários fontes, dados e informações confiáveis a fim de que sejam justificados e solucionados os desafios sociais, a sétima competência advoga que:

Argumentar com base em fatos, dados e informações confiáveis, para formular, negociar e defender ideias, pontos de vista e decisões comuns que respeitem e promovam os direitos humanos, a consciência socioambiental e o consumo responsável em âmbito local, regional e global, com posicionamento ético em relação ao cuidado de si mesmo, dos outros e do planeta.

Reforça-se assim a compreensão de que a cultura digital não é neutra e potencializa as contradições sociais e educacionais evidenciando a necessidade de provocar a tomada de consciência dos estudantes sobre informações, dados e dispositivos tecnológicos que perpassam essa Cultura. As duas competências gerais da Educação Básica ainda que abordem o uso crítico e reflexivo dessa Cultura, não explicitam algumas contradições inerentes à cidadania digital (COSTA,2019) que devem se compor com a dimensão ética.

Nesse cenário de modificações educacionais, culturais, sociais e tecnológicas, é necessário vislumbrar caminhos para que possamos continuar as transições dos Flintstones para os Jetsons de forma mais consciente, ética e igualitária. Portanto, ao apresentarmos as diversas formas 
de cultura, focalizando a cultura digital como potencializadora tanto para o desenvolvimento social quanto para a necessidade de rever a inclusão e a reorganização das relações sociais mediadas pelas TDIC, expomos um dos inúmeros cenários em que os aspectos culturais são enaltecidos. A educação, à vista disso, deve propor possibilidades para que os discentes e cidadãos possam transitar nessa cultura, sendo capazes de adotar e defender decisões baseadas em fatos, dados e informações confiáveis.

\section{Alfabetização midiática e informacional e o currículo: caminhos para as fake news}

Ao apresentarmos os aspectos culturais que perpassam o uso das TDIC, evidenciando algumas das inúmeras dimensões que se relacionam com o campo educacional, como as atuais modificações curriculares, procuramos proporcionar um breve panorama para as discussões sobre educação e fake news. Sem negligenciarmos o objetivo de compreender a relação entre educação e fake news, a partir da constituição de rede de autores e rede de palavras-chave, e a fim de identificar as possíveis convergências e perspectivas que possam ampliar a relação entre esses campos de estudo, propomos nesta seção organizar nossas reflexões em dois eixos: no primeiro, exporemos as distinções entre fake news, misinformation, disinformation, e, no segundo, discorreremos sobre a alfabetização midíatica e informacional como possibilidade para o enfrentamento das notícias errôneas.

No manual "Jornalismo, fake news \& desinformação: manual para educação e treinamento em jornalismo" [tradução nossa] (IRETON, POSETT; 2018), elaborado pela Organização das Nações Unidas para a Educação, a Ciência e a Cultura (Unesco), as fake news são apresentadas como desafios para a qualidade, impacto e credibilidade jornalística. Nesse documento são expostos três importantes e necessárias6 conceituações envolvendo as informações erradas, a saber:

\footnotetext{
6 Partindo da colocação de Valente $(2018$, p. 3), que aponta para "a bifurcação semântica com os prefixos 'mis' e 'dis'", não se encontra correspondência no português, no qual, para os dois, a tradução equivalente seria a de "desinformação", por isso consideramos apropriado exibir os termos no idioma inglês.
} 
Disinformation: informações falsas e criadas deliberadamente para prejudicar uma pessoa, grupo social, organização ou país;

Misinformation: informações falsas, mas não criadas com a intenção de causar danos;

Má informação: informações baseadas na realidade, usadas para infligir danos a uma pessoa, grupo social, organização ou país (IRETON, POSETT; 2018, s/p).

O documento "Entendendo as vulnerabilidades dos cidadãos à desinformação e à propaganda orientada a dados" (FLORE, BALAHUR, PODAVINI, VERILE; 2019) organizado pelo Joint Research Centre (JRC) e pela Unesco ressalta que um dos maiores riscos das notícias falsas, especialmente as do tipo disinformation, é o seu processo de apagar a história minando o pensamento crítico. Ou seja, a disinformation "mitiga o processamento consciente da informação, criando uma estrutura onde as contradições não são reconhecidas" (FLORE, BALAHUR, PODAVINI, VERILE; 2019, p.3).

Em um outro panorama, a quantidade expressiva de informações que os cidadãos estão interagindo pode fomentar uma percepção errônea do que está sendo divulgado impactando nas crenças e ações individuais. Flore, Balahur, Podavini e Verile (2019) apontam que as pessoas tendem a confiar em opiniões que confirmam convicções pré-existentes assim, reforçando notícias, fatos e dados que repetidas inúmeras vezes e com expressiva exposição aos indivíduos podem se tornar verdadeiras ou passíveis de escassa confirmação de sua veracidade.

Essas distinções conceituais, em um primeiro cenário, são necessárias para distinguir quais tipos de informações estão sendo divulgadas socialmente. Em um segundo panorama, esses conceitos apontam para a exigência de ações distintas para cada tipo de informação, isto é, ao acessar uma notícia, cabe ao usuário: 1) julgar a veracidade da informação 2) compreender as razões que sustentam a socialização e uso das informações, sejam elas verdadeiras ou falsas, discernindo impacto da divulgação das notícias; 3) em caso de dúvida, cabe ao usuário pesquisar a informação correta; 4) identificar se a notícia falsa tem alguma intenção de causar danos ou não; e 5) se possível, informar aos meios de divulgação que a informação apresentada não é verdade. 
Para Fernandez e Harith (2018), a participação do usuário no combate às informações errôneas é necessária a fim de fortalecer sua resiliência à má informação, haja vista que os esforços na identificação e na exclusão das notícias falsas por softwares e recursos tecnológicos ainda são ínfimos comparados ao quantitativo de notícias que são geradas cotidianamente. Logo, futuras pesquisas e recursos tecnológicos devem considerar quatro fatores com o propósito de incentivar a participação dos usuários:

Empoderamento: apresentar e reforçar nos sujeitos o conhecimento sobre as fontes e os tipos de conteúdo que podem ser falsos;

Engajamento: desenvolver redes de apoio e espaços de comunicação entre os sujeitos;

Educação: educar os sujeitos para a identificação e riscos das notícias falsas; e

Encorajamento: encorajar os sujeitos a identificar, invalidar e combater as notícias falsas.

Na perspectiva de inclusão dos usuários nessa seara, diversas iniciativas educacionais foram criadas com o intuito de promover espaços de debate, formação docente e promoção de práticas pedagógicas voltadas para o enfretamento das fake news. Nos trabalhos desenvolvidos pela Unesco, as concepções de alfabetização midiática e alfabetização informacional são interligadas para ponderar sobre o papel das mídias e das informações. A alfabetização midiática tem por objetivo viabilizar o desenvolvimento de conhecimentos, habilidades e atitudes para a integração entre a mídia tradicional e as novas tecnologias. Por sua vez, a alfabetização informacional requer que os cidadãos sejam capazes de interpretar e realizar julgamentos com base nas informações apresentadas, assim como possam tornar-se produtores de informação sobre seus próprios direitos.

Nessa interligação, a Unesco cunhou o termo alfabetização midiática e informacional (AMI), que almeja fornecer aos cidadãos conhecimentos, habilidades e atitudes para o uso consciente das mídias e das informações. Para tanto, no manual "Alfabetização midiática e informacional: diretrizes 
para a formulação de políticas e estratégias" (GRIZZLE, CALVO; 2016), são apresentas dez habilidades que envolvem a AMI, a saber:

1. compreender o papel e as funções das mídias e de outros provedores de informação nas sociedades democráticas;

2. compreender as condições nas quais essas funções possam ser realizadas;

3. reconhecer e articular a necessidade informacional;

4. Iocalizar e acessar informações relevantes;

5. avaliar com senso crítico, em matéria de autoridade, credibilidade e finalidade atual, a informação e o conteúdo das mídias e de outros provedores de informação, incluindo aqueles na Internet;

6. extrair e organizar a informação e o conteúdo midiático;

7. sintetizar ou trabalhar com as ideias abstraídas do conteúdo;

8. comunicar para um grupo de pessoas ou leitores, com ética e responsabilidade, sua compreensão sobre o conhecimento criado, em uma forma ou meio de comunicação apropriado;

9. aplicar as habilidades em TIC para processar a informação e produzir conteúdo gerado por usuários; e

10. engajar-se nas mídias e em outros provedores de informação, incluindo aqueles na Internet, para autoexpressão, liberdade de expressão, diálogo intercultural e participação democrática.

Além da AMI como uma das possibilidades de integrar as mídias e repensar o uso das informações nos cenários educacionais, como expomos anteriormente, as modificações curriculares também ganham grande destaque, a exemplo das ponderações apresentadas anteriormente ao tratarmos da BNCC.

Considerando um currículo como uma prática social estruturada em procedimentos, métodos, conteúdos e atividades que se constituem a partir das demandas sociais, políticas, econômicas e da modificação dos perfis profissionais, sendo repensado em razão dos contextos de aprendizagem e contextos culturais (ALMEIDA, VALENTE; 2011). 
Nesse sentido, tanto a AMl quanto as possíveis ações de integração entre as TDIC e o currículo, quando apresentadas como caminhos para aprofundarmos sobre a relação entre educação e fake news, como expomos, exigem que pensemos sobre os contextos de aprendizagem em que essas temáticas estão inseridas. Utilizamos como inspiração o estudo de Figueiredo (2016), que define contextos de aprendizagem como "um conjunto coerente de fatos, circunstâncias e pessoas que acompanham e concretizam uma situação de aprendizagem - o que acontece, para e por que acontece, onde acontece, como acontece, quando acontece e a quem acontece" (p. 811). Almeida (2016) acrescenta que os contextos de aprendizagem integram os contextos formais, informais e não formais de ensino, transpondo o formato tradicional de aulas e promovendo comunidade de práticas, de aprendizagem e construção do conhecimento.

Espera-se que as produções acadêmicas, como artigos, que versam sobre educação e fake news sejam capazes de compreendê-las a partir de um olhar que incorpore distintos contextos de aprendizagem, não somente, ou predominantemente, o contexto formal. Nessa conjuntura, discorrer sobre as fake news, disinformation, misinformation e má informação, em um primeiro prisma, exige fomentar perspectivas de participação crítica, consciente e ética dos usuários na compreensão dos tipos de informações falsas disponíveis e na utilização indevida dessas notícias. Em um segundo prisma, em um cenário de vertiginosas modificações culturais, principalmente envolvendo $O$ digital, ações educacionais que compreendam a $\mathrm{AMI}$ e o (re)pensar o currículo, concebendo a integração das TDIC, é uma urgência que se impõe.

\section{Design metodológico}

Ao objetivarmos compreender a relação entre educação e fake news a partir da constituição de rede de autores e rede de palavras-chave, identificando as possíveis convergências e perspectivas que possam ampliar a relação entre esses campos de estudo, para esta pesquisa julgamos que as fake news encontram-se majoritariamente em um cenário permeado pela 
virtualidade. Portanto, desconsiderar a possibilidade de análises desses rastros digitais seria menosprezar uma fonte inestimável para o entendimento das convergências e perspectivas entre a educação e fake news, sobre as quais almejamos discorrer neste estudo.

Nesse sentido, com o advento dos métodos digitais amparados pelas TDIC, os rastros digitais podem cada vez mais servir de insumo para 0 entendimento das redes que permeiam a cultura digital, proporcionando que áreas de estudos possam ampliar seus respectivos campos de atuação. Os métodos digitais, como as visualizações propiciadas pelas análises de redes sociais, tornaram-se relevantes recursos para a identificação de tendências teóricas e/ou metodológicas e visualização de redes de autores, redes temáticas, redes de palavras-chave, entre outros. ${ }^{7}$

Nesse cenário, julgamos que a união entre as visualizações de redes, provindas da análise de redes sociais e as análises bibliométricas, seria um passo importante para compor esta pesquisa exploratória. Dessarte, como procedimentos para coleta dos artigos científicos, adotamos como critérios de seleção os seguintes requisitos:

1) Descritor de levantamento: education AND "fake news";

2) Artigos acadêmicos;

3) Artigos de 2013 a 2019;

4) Artigos avaliados por pares;

5) Artigos com acesso aberto; e

6) Artigos que contemplem temáticas educacionais.

Por sua vez, 0 repositório Science Direct (https://www.sciencedirect.com/) contempla mais de 15.000 livros eletrônicos e mais de 2.500 títulos de revistas científicas de diversas áreas, como Ciências Sociais e Humanidades, Tecnologia e Medicina. A seleção da Science Direct para a composição desta pesquisa justifica-se, em primeiro plano, pelo amplo quantitativo de produções disponibilizadas e, em segundo plano, pela possibilidade de criar redes de forma automática por

\footnotetext{
${ }^{7}$ Ver artigo Mapping the Open Education Landscape: Citation Network Analysis of Historical Open and Distance Education Research.
} 
dispositivos de visualização de dados. Para este estudo utilizaremos o software gratuito de visualização de redes, vosviewer.

Vale destacar que, ao adotarmos os critérios de seleção, somente catorze artigos contemplavam todas as exigências. Nesse sentido, pela escassez de artigos que interligam as temáticas educação e fake news, somente dois tipos de redes puderam ser visualizados: as redes de autores e as redes de palavras-chave.

\section{Educação e fake news: o que dizem as redes?}

Ao procurarmos entender as convergências e as perspectivas que possam ampliar a relação entre educação e fake news a partir da busca no repositório Science Direct, verificamos que dos trinta e um resultados apresentados inicialmente somente quatorze artigos preenchiam todos os critérios de seleção adotados para este estudo.

Dos quatorze artigos, dez foram publicados em 2019 e os demais em 2018. Essa informação é importante porque se trata de uma temática bastante recente, considerando que o uso do termo fake news relacionado com a cultura digital teve sua ampliação após as eleições americanas de 2016.8 Assim, conceitos que, embora não sejam recentes ao serem incorporados aos elementos da cultura digital, carregam outros sentidos e significados, como as expressões fake news, misinformation, disinformation e mal-information. A ausência de produções anteriores a 2017 marca o despontar de temáticas e áreas de pesquisa que ainda estavam no campo das ideias, haja vista que os artigos acadêmicos, em geral, são concebidos um ano antes de sua publicação. Portanto, para que as produções acadêmicas pudessem ser publicadas em 2017, seria necessária, ainda em 2016, a consciência do impacto das fake news naquele momento histórico.

Como apresentam Recuero, Bastos e Zago (2015, p. 56), o cluster "é compreendido como um agregado mais denso que o restante da rede, ou seja, um conjunto de nós aproximados por um maior número de conexões ou

8 Disponível em: https://www.huffpostbrasil.com/entry/fake-news-oxford-englishdictionary_n_5d9e297ce4b06ddfc512dle4? ri18n=true. Acesso em: Janeiro de 2020. 
por conexões mais pesadas na rede". De acordo, com a rede de autores gerada pelo VOSviewer, foram visualizados catorze aglomerados, isto é, cada artigo configurou-se como um cluster9 (Imagem 1). Diferentemente de outras redes de autores, em que um nó pode servir de ligação para outros clusters ou redes (WELLER; JORDAN; DEVRIES; ROLFE, 2018), verificamos que não foram estabelecidas ligações do tipo cluster para cluster; elas se limitaram aos autores de um mesmo cluster, isto é, um autor poderia ter participado da elaboração de mais de um artigo, estabelecendo, assim, a ligação entre dois clusters ou redes.

Nessa conjuntura, para Buzato (2014, p. 8), ao possibilitar a identificação de "regras formais vinculadas às relações topológicas e quantitativas entre atores", a análise de redes sociais fica à mercê de um volumoso conjunto de dados e de escalas de interação capazes de prever as relações. Portanto, algumas das hipóteses para a ausência de ligações entre clusters podem ser: 1) o escasso número de artigos que relacionem as temáticas educação e fake news presentes no repositório Science Direct; e 2) a atualidade temática que impulsiona, em um primeiro momento, o desenvolvimento de pesquisas no âmbito de um grupo de pesquisa ou de pesquisadores de uma mesma instituição ou pesquisadores de um mesmo país. Dos catorze artigos somente quatro detêm pesquisadores de instituições ou países distintos.

IMAGEM 1: Rede de Autores

9 Para Recuero, Bastos e Zago (2015), cluster é um conjunto de nós mais densamente conectados que o resto da rede. 


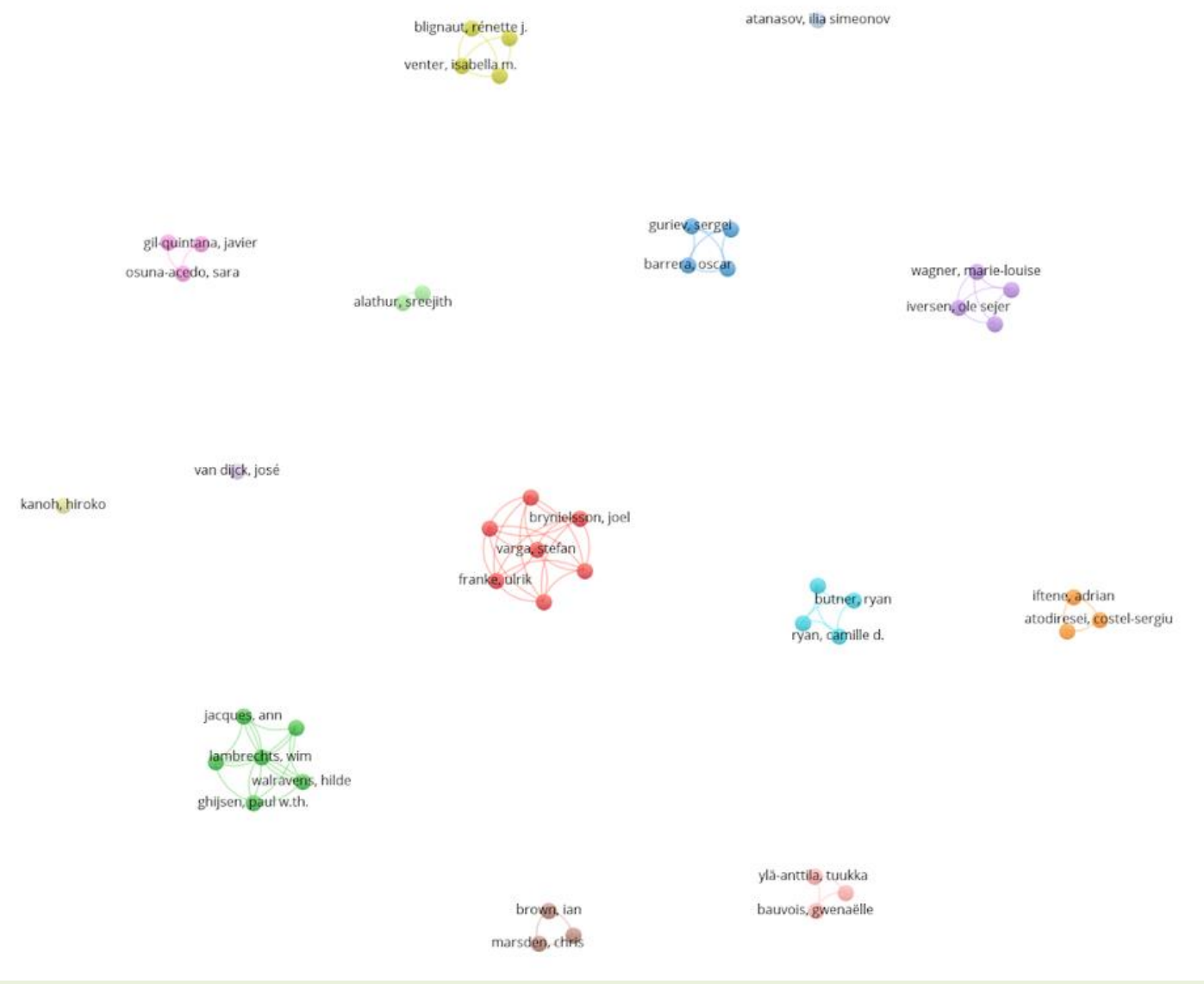

Fonte: VOSviewer.

Em uma análise mais detalhada, as produções selecionadas reforçaram o caráter transdisciplinar que percorre os estudos sobre as fakes news considerando que houve maior concentração de estudos envolvendo as áreas: educação, governança, segurança da informação e computação. No que concerne à educação, apesar de a temática educacional estar presente nas catorze pesquisas, evidencia-se que ora a educação é vista a partir de dois ângulos: o primeiro insere-se como um dos componentes que merecem atenção, quando relacionados com as fake news, e o segundo como campo para o desenvolvimento da pesquisa (TUHKALA; WAGNER; IVERSEN; KA'RKKAIINEN, 2019; LAMBRECHTS; GHIJSEN; JACQUES; WALRAVENS; LIEDEKERKE; PETEGEM, 2019).

O primeiro ângulo, que envolve majoritariamente as áreas de governança, segurança da informação e computação, inclui dentre os componentes a regulamentação das informações, as eleições, os processos comunicacionais, a criação de softwares de identificação de fake news e, 
também, a educação como um elemento influenciado pelas notícias errôneas. Nessa perspectiva, o campo educacional é uma dentre tantas áreas afetadas pelas fake news.

Na área da governança, os artigos (BARRERA; GURIEV; HENRY; ZHURAVSKAYA, 2019; RYAN; SCHAUL; BUTNER SWARTHOUT, 2019) versam acerca: 1) das eleições, demonstrando que a verificação dos fatos melhoram o conhecimento dos leitores, no entanto não afetam os posicionamentos de apoio das políticas ou dos candidatos (BARRERA; GURIEV; HENRY; ZHURAVSKAYA, 2019); e 2) das modificações genéticas de alimentos, tendo o estudo sobre alimentos transgênicos mostrado que os sites que publicam mais informações errôneas são os que possuem maior engajamento (RYAN; SCHAUL; BUTNER; SWARTHOUT, 2019).

Por sua vez, no tocante à área de segurança da informação, as pesquisas discursam a respeito da regulamentação das mídias sociais e das informações presentes na Internet, temática que também poderia ser inserida no campo da governança (DIJCK, 2019; MARSDEN; MEYER; BROWN, 2019; VENTER, J. BLIGNAUT; RENAUD; VENTER, 2019). Por seu turno, os estudos da área de computação (MARSDEN; MEYER; IAN BROWN, 2019; LOZANO; BRYNIELSSON; FRANKE; ROSELL, 2019; CHETTY; ALATHUR, 2019) enfatizaram a construção de softwares (CHETTY; ALATHUR, 2019) ou recursos tecnológicos, como Inteligência Artificial (MARSDEN; MEYER; IAN BROWN, 2019) e Machine Learning (LOZANO; BRYNIELSSON; FRANKE; ROSELL, 2019) na identificação de fake news.

Considerando o segundo ângulo, que reforça o campo educacional, dois estudos merecem destaque. O estudo de Tuhkala et al. (2019) apresenta a proposta de implementação da disciplina "Compreensão tecnológica" nas escolas secundárias da Dinamarca. A matéria percorre as temáticas de computação, design e reflexão sobre assuntos que envolvem a cultura digital, entre elas as fake news. O artigo conclui que (1) os professores advogam com os conhecimentos tecnológicos devem compor um conjunto de habilidades que podem ser integradas em outros assuntos e não como uma disciplina distinta; (2) os professores apontaram que a compreensão 
tecnológica se abre para atividades de aprendizagem interdisciplinares e envolventes, mas eles precisam de mais andaimes e apoio; (3) a compreensão tecnológica desafia as competências existentes dos professores e é necessária uma estrutura que leve em conta a computação, o design e a reflexão da sociedade como um todo; (4) a compreensão tecnológica atraiu vários tipos de estudantes, não apenas aqueles entusiasmados com questões técnicas.

Em adição, objetivando compreender as atitudes que os estudantes possuem sobre a sustentabilidade, Lambrechts et al. (2018) expõem que, em meio à era da pós-verdade, da desinformação e das fake news, a criticidade e a alfabetização midiática e informacional são relevantes para o entendimento dos desafios que envolvem a sustentabilidade. Para esses autores, a sustentabilidade deve munir-se de "diversidade de abordagens para preparar os alunos para lidar com a complexidade e a incerteza das questões de sustentabilidade, orientadas para um aprendizado mais autorregulado para $O$ desenvolvimento de competências críticas e interpretativas" (LAMBRECHTS et al., 2018, p. 1).

Por seu turno, na rede de palavras-chave (Imagem 2), três palavras foram mais frequentes: fake news, rede social e educação. É importante salientar que o termo social media, assim como os termos misinformation e disinformation, carregam dubiedade quando traduzidos, podendo tanto representar rede social ou mídia social. Para Recuero, Bastos e Zago (2015, p. 29), a mídia social "se refere a um fenômeno emergente, que tem início com a apropriação de site de rede social pelos usuários". Nesse sentido, a mídia social como campo de estudo, envolve diversos elementos da Internet e das TDIC, e não somente redes sociais, como Twitter, Facebook e YouTube. Julgamos, no entanto, que seria mais adequado traduzir social media para rede social, haja vista que os artigos versam, em sua maioria, sobre o Twitter e Facebook.

Na visualização da rede de palavras-chave é possível observar dois grupos: um formado pelos termos fake news e redes sociais; e outro pelo termo educação. Essa separação evidencia que, apesar de as três palavras 
serem as mais recorrentes nos catorze artigos, possibilitando a percepção pelo VOSviewer, existe uma maior convergência entre as temáticas fake news e redes sociais em comparação com as possíveis convergências que poderiam emergir a partir da associação entre educação e fake news. Ao apresentarmos a análise dos artigos a partir das áreas - educação, governança, segurança da informação e computação -, a separação entre fake news/redes sociais e educação fica mais evidente. Como expusemos, somente dois trabalhos apresentavam relações entre educação e fake news (TUHKALA et al., 2019; LAMBRECHTS et al., 2018) e os demais abordavam o campo educacional como coadjuvante. Sob a perspectiva da visualização de redes, a maior concentração de trabalhos que não abordam diretamente a educação fica representada pela separação entre esses dois grupos.

IMAGEM 2: Rede de palavras-chave

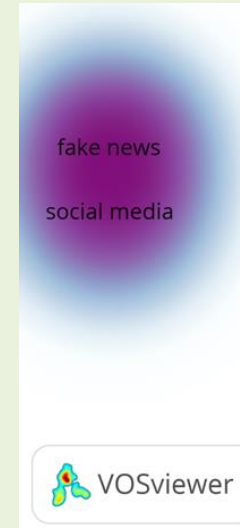

education

Fonte: VOSviewer.

Ao analisarmos as palavras-chave a partir de uma categorização semântica (FRANCO, 2008), nota-se que os artigos científicos sugerem ter como conteúdos gerais seis eixos: 
1. Mídias sociais (fake news, Twitter, pós-verdade, pós-fato, informação, desinformação, rumores, incerteza, conteúdo de ódio, segmentação, credibilidade, qualidade das informações).

2. ${ }^{\circ}$ Segurança (cyber security, verificação dos fatos, projeção dos fatos, valores da plataforma, avaliação da veracidade, cibercrime relacionado ao gênero).

3. Governança (regulação, governança da Internet, economia da atenção, organismos geneticamente modificados, Lei da Internet, experiência econômica, eleições, regulação da mídia social, regulação das plataformas).

4. Educacional (educação; estudantes, professores; ensino superior; pensamento computacional).

5. Computação (estrutura de computação móvel, smartphone, plataformas, inteligência artificial, Internet, design).

6. Usuário (autorregulação, corregulação, atitudes, competências, sujeito).

A organização das palavras-chave em eixos permite, mesmo que em linhas gerais, vislumbrar horizontes para a expansão das produções acadêmicas e das reflexões sobre a educação e as fake news. Nessa perspectiva, ousamos apresentar algumas possibilidades de aproximação entre esses campos de estudos.

Embora as principais expressões contidas no eixo mídias sociais sejam, majoritariamente, de cunho negativo, consideramos pertinente apresentar as possibilidades de integração entre o contexto educacional e as mídias sociais No levantamento bibliográfico desenvolvido por Santos e Almeida (2017), cujo objetivo foi identificar como as produções científicas brasileiras discorrem sobre a relação entre as redes sociais, um dos artefatos que pertencem às mídias sociais, e a educação, foi possível observar que esses instrumentos como recursos pedagógicos podem contribuir para a ampliação das relações sociais, o estabelecimento de novas configurações de interação por meio do uso de avatares, curtidas, compartilhamentos, vídeos, memes, reações. Ademais, podem ser utilizadas com a finalidade de 
potencializar a conexão entre contextos formais, não formais e informais, ampliando os espaços formativos (ALMEIDA; VALENTE, 2014).

Por seu turno, no eixo segurança, alguns termos - verificação dos fatos, projeção dos fatos e avaliação da veracidade - são recorrentes no âmbito dos estudos sobre fake news. Partindo da necessidade de compreender as ameaças do ambiente da Internet, englobando as notícias falsas dentre suas inúmeras iniciativas educacionais, o Centro de Estudos, Resposta e Tratamento de Incidentes de Segurança no Brasil (CERT.br) produziu a Cartilha de Segurança da Internet, que aborda entre suas temáticas: privacidade dos dados, golpes da Internet, ataques na Internet e cuidados com os boatos na rede.

No âmbito da governança, temática de maior repercussão atualmente, aponta-se para os desafios da regulação das mídias sociais e da Internet, especialmente considerando os prejuízos que as fake news podem causar à sociedade. Do ponto de vista educacional, Freire (1974, p. 26), ao afirmar que "alfabetização política" revela a falta de compreensão crítica ou dialética do homem, quando encara as suas próprias relações com o mundo", tal sentença dá margem à compreensão das questões políticas e de governança.

A regulação das mídias sociais e da Internet salienta duas complementares fases sobre a governança e a política: a primeira fase mostra a fragilidade dos cidadãos, seja na ingenuidade em divulgar notícias falsas/errôneas ou na falta de compreensão sobre os riscos das fake news; a segunda fase mostra a participação ativa das instâncias governamentais ao estabelecerem instrumentos legais que podem tanto ser utilizados para coibir as notícias falsas quanto para censurar as verdadeiras. Em ambas as fases, a alfabetização política é requerida, os cidadãos, ao terem compreensão crítica sobre suas relações com o mundo, são capazes de indagar acerca da veracidade dos fatos, dados e informações, podendo, assim, tanto realizar escolhas mais adequadas na divulgação de informações quanto ser atuantes na seleção de quais aspectos devem ser encarados na regulação das mídias sociais e da Internet. 
No cerne do eixo educacional, a expressão "pensamento computacional" destaca-se em meio a termos habituais da área educacional, como educação; estudantes, professores e ensino superior. Para Wing (2010), pensamento computacional trata-se de "processos de pensamento envolvidos na formulação de problemas e suas soluções, sendo que as soluções devem ser representadas de forma que possa ser realizada por agentes de processamento de informações" (CUNY; SNYDER; WING, 2010, apud WING, 2011, p. 20). Assim, na esfera educacional, o pensamento computacional estaria relacionado tanto à reflexão quanto ao uso de artefatos tecnológicos para a resolução de possíveis problemas sociais, entre eles as fake news.

Por sua vez, no eixo computação, duas palavras merecem especial atenção, "estrutura de computação móvel" e "smartphone". As Tecnologias Móveis com Conexão Sem Fio à Internet (TMSF), representadas por essas palavras-chave, ampliaram as possibilidades de uso das TDIC, incorporando cada vez mais esses recursos às ações e aos comportamentos das pessoas de diferentes classes sociais (IANNONE; ALMEIDA; VALENTE, 2015). Em estudo sobre a TMSF, Almeida (2016) apresenta as possibilidades de integrar os espaços de aprendizagem formais aos espaços não formais e informais em uma perspectiva de complementaridade (LAURILLARD, 2007) e de integração entre contextos de aprendizagem por meio do uso intenso das TMSF (PRICE, 2007) em tempos de computação e aprendizagem ubíqua (SANTAELLA, 2013). AS TSMF, nesse sentido promovem a

[...] mobilidade do currículo, da formação e da aprendizagem; a superação dos limites do espaço e tempo específicos para a aprendizagem com a expansão da educação formal; a criação de contextos de aprendizagem formal, não formal e informal e a articulação entre eles decorrente de atividades intencionais; (ALMEIDA, 2016, p. 541).

Nesse sentido, as TMSF exercem influência sobre as ações, comportamentos e atitudes, ampliando as possibilidades de inserção dos usuários na cultura digital. Na educação, as TMSF contribuem para a integração entre contextos de aprendizagem formal, não formal e informal, 
superando os limites de espaço e tempo específicos para a aprendizagem favorecendo a articulação entre contextos da prática de formação e propiciando estudos sobre experiências autênticas do trabalho e das distintas esferas da vida.

No que diz respeito à participação do usuário no combate às fake news (FERNANDEZ, HARITH; 2018), os termos mais frequentes foram: autorregulação, corregulação, credibilidade do usuário, atitudes e competências individuais. Além de as pesquisas acadêmicas (SANTOS, ALMEIDA, 2017a; SANTOS, ALMEIDA, 2017b) vislumbrarem caminhos para a participação ativa, ética e consciente dos usuários no enfretamento das informações falsas ou iniciativas (COSTA, 2019), elas buscam conscientizar e explicitar o que são, quais implicações que envolvem as fake news e como checar os fatos. Dentre as inúmeras iniciativas, a Intervozes - Coletivo Brasil de Comunicação Social, que atua no direito à comunicação brasileiro, lançou a cartilha "Desinformação: ameaça ao direito à comunicação muito além das fake news". Nesse documento, são expostas conquistas sociais como a Lei Geral de Proteção dos Dados Pessoais (LGPD) e o Marco Civil da Internet, bem como evidenciados os limites de atuação dos usuários impostos pelas empresas de comunicação. Em um dos exemplos, a cartilha apresenta os casos de zero-rating, prática comercial que valoriza de forma "gratuita" o uso de determinado aplicativo, como as Redes Sociais da Internet, e limita outros, como o acesso à Internet.

Nesse cerne, considerando as desigualdades de acesso à informação, a participação do usuário deve perpassar a $\mathrm{AMI}$, a fim de conduzir práticas pedagógicas que envolvam questionamentos, indagações e consciência social, atitudes que não se limitam somente ao cenário da cultura digital.

Ao procurarmos entender as convergências e perspectivas que possam ampliar a relação entre educação e fake news a partir da busca no repositório Science Direct, verificamos que há a necessidade de ampliar as produções que versem sobre essas duas temáticas. Na seleção dos artigos, apesar da variedade de áreas - educação, governança, segurança da informação e computação - que se dedicam ao entendimento das fake 
news, somente dois (TUHKALA et al., 2019; LAMBRECHTS et al., 2018) se concentraram na convergência entre educação e fake news. Por sua vez, na análise das palavras-chave, confirmaram-se as diferentes áreas que permeiam o entendimento das fake news apontando para possibilidade de integração com a educação tema que pretendemos aprofundar em outros estudos.

\section{CONCLUSÃO}

O presente artigo, cujo objetivo foi compreender a relação entre educação e fake news, a partir da constituição de rede de autores e rede de palavras-chave, identificando as possíveis convergências e perspectivas que possam ampliar a relação entre esses campos de estudo, por meio de um estudo bibliométrico das produções acadêmicas desenvolvidas no período de 2013 a 2019, disponíveis no repositório Science Direct, expressou a necessidade de estender os estudos sobre essa temática.

A rede de autores não evidenciou associações entre autores de diferentes instituições ou país na conexão entre cluster-cluster. Consideramos que a ausência de relações do tipo cluster-cluster justifica-se pela atualidade da temática que impulsiona, em um primeiro momento, o desenvolvimento de pesquisas no âmbito de um grupo de pesquisa ou de pesquisadores de uma mesma instituição ou pesquisadores de um mesmo país. A rede de autores também ressaltou a necessidade de ampliar a pesquisa, considerando outros repositórios. Por sua vez, a rede de palavras-chave evidenciou seis eixos de conteúdos gerais: mídias sociais, segurança, governança, educacional, computação e usuário -, reforçando as transdisciplinaridades que envolvem os estudos sobre fake news.

Nesse cerne, as futuras pesquisas devem abranger mais repositórios digitais em vias de identificar possíveis elos de autoria, instituição e temáticas que perpassam a educação e as fake news. Consideramos que o estudo permitiu desvendar possibilidades na integração entre Educação e Fake news sinalizando a importância da formação ativa, ética e consciente dos 
cidadãos no uso das Mídias Sociais, aspecto que deve ser exaltado nas iniciativas educacionais.

\section{REFERÊNCIAS}

ALMEIDA, M. E. B. T. M. P. de. Currículo e narrativas digitais em tempos de ubiquidade: criação e integração entre contextos de aprendizagem. Revista Educação Pública, v. 25, n. 59/2, p. 526-546, 2016.

ALMEIDA, M. E. B. T. M. P. Integração currículo e Tecnologias de Informação e Comunicação: Web currículo e formação de professores. 2019. Tese (LivreDocência) - Pontifícia Universidade Católica de São Paulo, 2019.

ALMEIDA, M. E. B. T. M. P.; VALENTE, J. A. Tecnologias e currículo: trajetórias convergentes ou divergentes? São Paulo: Paulus, 2011.

ALMEIDA, M. E. B. T. M. P.; VALENTE, J. A. Currículo e contextos de aprendizagem: integração entre o formal e o não formal por meio de tecnologias digitais. Revista e-Curriculum, v. 12, n. 2, p. 1162-1188, 2014.

ATANASOV, I. S. Uncertainty in social networks: a matter of opinions. IFACPapersOnLine, v. 52, n. 25, p. 494-497, 2019.

ATODIRESEI, C.-S.; TĂNĀSELEA, A; IFTENE, A. Identifying fake news and fake users on Twitter. Procedia Computer Science, v. 126, p. 451-461, 2018.

BARRERA, O. et al. Facts, alternative facts, and fact checking in times of posttruth politics. Journal of Public Economics, v. 182, p. 104123, 2020.

BOOMERANG OFFICIAL. The Jetsons - A day in the life of a Jetson. YouTube, Disponivel em: https://www.youtube.com/watch?v=ayWyniqrT3w. Acesso em: 25 jan. 2020.

BRASIL. Base Nacional Comum Curricular (BNCC). Educação é a base. Brasília, MEC/CONSED/UNDIME, 2017. Disponível em:

http://basenacionalcomum.mec.gov.br/images/BNCC_publicacao.pdf. Acesso em: 25 jan. 2020.

BUCKINGHAM, D. Cultura digital, educação midiática e o lugar da escolarização. Educação \& Realidade, v. 35, n. 3, p. 37-58, 2010.

BUZATO, M. E. K. Cultura digital, educação e letramento: conflitos, desafios, perspectivas. In: HÖFLING, C. (org.). Jornada de letras. São Carlos: Editora da UFSCar, 2010. p. 69-88. 
BUZATO, M. E. K. 29. Encontro Nacional da ANPOLL (Associação Nacional de Pós-graduação e Pesquisa em Letras e Linguística), realizado de 9 a 11 de junho de 2014 na Universidade Federal de Santa Catarina, Florianópolis - SC.

CASTELLS, M. Redes de indignação e esperança: movimentos sociais na Era da Internet. Rio de Janeiro: Zahar, 2013.

CHETTY, N.; ALATHUR, S. An architecture for digital hate content reduction with mobile edge computing. Digital Communications and Networks, 2019.

COSTA, D. A educação para a cidadania digital na escola: análise multidimensional da atuação dos professores enquanto mediadores da cultura digital nos processos de ensino e de aprendizagem. 2019. Tese (Doutorado) - Pontifícia Universidade Católica de São Paulo, São Paulo, 2019.

FERNANDEZ, M.; ALANI, H. Online Misinformation: Challenges and Future Directions. In: WWW' 18 COMPANION: The 2018 WEB CONFERENCE COMPANION. ACM, NeW York, 2018, p. 595-602.

FIGUEIREDO, A. D. A pedagogia dos contextos de aprendizagem. Revista eCurriculum, v. 14, n. 3, p. 809-836, 2016.

FERREIRA, N. S. A. As pesquisas denominadas "estado da arte". Educação \& Sociedade, v. 23, p. 257, 2002.

FLORE, M.; BALAHUR, A.; PODAVINI, A.; VERILE, M. Understanding citizens' vulnerabilities to disinformation and data-driven propaganda, EUR 29741 EN, Publications Office of the European Union, Luxembourg, 2019, ISBN 978-92-7603320-2, doi:10.2760/919835, JRC 116009.

FRANCO, M. L. P. B. Análise de conteúdo. Campinas: Autores Associados, 2008.

FREIRE, P. O processo de alfabetização política. Rev. da FAEEBA, Salvador, n. 7, p. 19-33, 1974.

FULLER, S. Post-truth: knowledge as a power game. London: Anthem Press, 2018.

GERE, C. Digital culture. London: Reaktion Books, 2009.

GRIZZLE, A; CALVO, M. C. T. Alfabetização midiática e informacional: diretrizes para a formulação de políticas e estratégias. Brasília/DF: Unesco, 2016.

IANNONE, L. R.; ALMEIDA, M.E. B; VALENTE, J. A. Pesquisa TIC Educação: da inclusão para a cultura digital. Pesquisa sobre o uso das tecnologias de informação e comunicação nas escolas brasileiras: TIC Educação, 2015. 
IRETON, C.; POSETTI, J. Journalism, fake news \& disinformation: handbook for journalism education and training. Unesco Publishing, 2018.

KENSKI, V. M.. Novas tecnologias: o redimensionamento do espaço e do tempo e os impactos no trabalho docente. Revista Brasileira de Educação, São Paulo, n. 8, p. 58-71, ago. 1998. Disponível em: $\mathrm{http}$ ://pitagoras.unicamp.br/ teleduc/cursos/diretorio/tmp/1808/portfolio/ite m/61/Impactonotrabalhodocente_kenski.pdf. Acesso em: 25 jan. 2020.

$\mathrm{KANOH}, \mathrm{H}$. Why do people believe in fake news over the Internet? An understanding from the perspective of existence of the habit of eating and drinking. Procedia Computer Science, v. 126, p. 1704-1709, 2018.

LAMBRECHTS, W. et al. Sustainability segmentation of business students: Toward self-regulated development of critical and interpretational competences in a post-truth era. Journal of Cleaner Production, v. 202, p. 561570, 2018.

LATOUR, B. Reagregando o social: uma introdução à teoria do ator-rede. Salvador: EDUFBA, 2012.

LOZANO, M. G. et al. Veracity assessment of online data. Decision Support Systems, v. 129, p. 113132, 2020.

MARSDEN, C.; MEYER, T.; BROWN, I. Platform values and democratic elections: how can the law regulate digital disinformation?. Computer Law \& Security Review, p. 105-373, 2019.

PEQUERNO ACERVO. Os Flintstones - Abertura e encerramento originais. YouTube. Disponível em:

https://www.youtube.com/watch?v=lo5ARXRpEds. Acesso em: 25 jan. 2020.

PRETTO, N. de L.; ASSIS, A. Cultura digital e educação: redes já. Além das redes de colaboração: internet, diversidade cultural e tecnologias do poder. Salvador: EDUFBA, 2008. p. 75-83.

ROJO, R. Alfabetização e letramentos múltiplos: como alfabetizar letrando. Coleção explorando o ensino: Língua Portuguesa: ensino fundamental. Brasília: Ministério da Educação, Secretaria de Educação Básica, 2010. v. 19, p. 15-36.

ROJO, R. ; MOURA, E. Multiletramentos na escola. São Paulo: Parábola, 2012. RECUERO, R; BASTOS, M; ZAGO, G. Análise de redes para mídia social. Porto Alegre: Sulina, 2015. 
RYAN, C. D. et al. Monetizing disinformation in the attention economy: the case of genetically modified organisms (GMOs). European Management Journal, 2019.

SANTAELLA, L. Desafios da ubiquidade para a educação. Revista Ensino Superior Unicamp, v. 9, p. 19-28, 2013.

SANTOS, P. C ; ALMEIDA, M. E. B. T. M. P.. O Facebook como integração entre o contexto formal e informal. In: ATAS DA X CONFERENCIA INTERNACIONAL DE TECNOLOGIAS DE INFORMACẪO E COMUNICAÇÃO NA EDUCACÂAO CHALLENGES 2017. Anais... Braga, de 8 a 10 de maio de 2017. Disponível em: http://www.nonio.uminho.pt/challenges/atas/.

SCIENCE DIRECT. Disponível em: https://www.sciencedirect.com/. Acesso em: 8 jan. 2020.

THE OXFORD ENGLISH DICTIONARY. Edited by John Simpson and Edmund Weiner. New York: Oxford University Press, 1989.

TUHKALA, A. et al. Technology comprehension - Combining computing, design, and societal reflection as a national subject. International Journal of Child-Computer Interaction, v. 20, p. 54-63, 2019.

VAN DIJCK, J. Governing digital societies: private platforms, public values. Computer Law \& Security Review, p. 105-377, 2019.

VENTER, I. M. et al. Cyber security education is as essential as "the three R's". Heliyon, v. 5, n. 12, p. e02855, 2019.

VOSVIEWER. Disponível em: https://www.vosviewer.com/. Acesso em: 8 jan. 2020.

WELLER, M. et al. Mapping the open education landscape: citation network analysis of historical open and distance education research. Open Praxis, $v$. 10, n. 2, p. 109-126, 2018.

Recebido em: 28 de fevereiro de 2020 Aprovado em: 12 de junho de 2020 Publicado em: 30 de julho de 2020

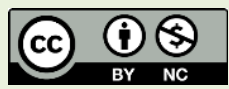

